Pesq. Vet. Bras. 37(12):1479-1482, dezembro 2017 DOI: 10.1590/S0100-736X2017001200019

\title{
Imunomarcação da transição epitélio-mesenquima na neoplasia mamária primária de cadelas e sua metástase em linfonodo ${ }^{1}$
}

\author{
Larissa Fernandes Magalhães ${ }^{2 *}$, Geórgia Modé Magalhães ${ }^{3}$, Sabryna Gouveia \\ Calazans ${ }^{4}$, Leandro Zuccolloto Crivellenti ${ }^{4}$, Gabriela Piovan Lima ${ }^{4}$ e Alessandra \\ Aparecida Medeiros-Ronchi ${ }^{2}$
}

\begin{abstract}
Magalhães L.F., Magalhães G.M., Calazans S.G., Crivellenti L.Z., Lima G.P. \& Medeiros-Ronchi A.A. 2017. [Epithelial to mesenchymal transition immunostaining in canine primary mammary tumor and lymph node.] Imunomarcação da transição epitélio-mesenquima na neoplasia mamária primária e no linfonodo em cadelas. Pesquisa Veterinária Brasileira 37(12):1479-1482. Departamento de Patologia Animal, Universidade Federal de Uberlândia, Av. Mato Grosso 3289, bloco 2S, Bairro Umuarama, Uberlândia, MG 38405314, Brazil. E-mail: larissa.magalhaes@unifran.edu.br

Mammary carcinomas in dogs have a high metastatic capacity which gives a shorter survival rate for patients with this type of tumor. The epithelial-mesenchymal transition phenotype, characterized by the trade of intermediary filaments of cytokeratin by vimentin, also by the loss of the adhesion protein between cells (E-cadherin) is associated with metastasis. Due to this fact, it was aimed to evaluate, by immunostaining, the expression of vimentin, cytokeratin and E-cadherin in canine mammary tumors and the metastasis in lymph node, in order to assess the cell behavior when facing this cancer. Five cases of canine mammary tumors and metastasis in lymph node were evaluated. The averages of immunostainings of the group of primary neoplasms were compared with the averages of the lymph node group. The results showed that immunostaining for cytokeratins $(p=0,1407)$ and E-caderina $(\mathrm{p}=0,312)$ were not significant between the groups, despite the expression mean of cadherin was higher in the metastase group. The expression of vimentin $(p=0,04)$ was greater at sites of metastases. It is concluded that the expression of vimentin increases in the focus of the metastase in relation to their respective primary canine mammary tumors, characterizing cellular structural alteration, conferring a transient epithelial-mesenchymal phenotype. And cadherin present strong evidence of increased focus on metastasis characterizing increased adhesion.
\end{abstract}

INDEX TERMS: Dogs, invasion, oncology, proteins, mammary tumors, lymph node.

RESUMO.- Os carcinomas mamários em cães apresentam alta capacidade metastática o que confere menor sobrevida para os pacientes com este tipo de neoplasia. 0 fenótipo

\footnotetext{
${ }^{1}$ Recebido em 22 de março de 2017.

Aceito para publicação em 31 de março de 2017.

2 Departamento de Patologia Animal, Universidade Federal de Uberlândia (UFU), Av. Mato Grosso 3289, bloco 2S, Bairro Umuarama, Uberlândia, MG 38405314, Brasil.*Autor para correspondência: larissa.magalhaes@ unifran.edu.br

${ }^{3}$ Departamento de Patologia Animal, Instituto Federal Sul de Minas, Estrada de Muzambinho Km 35, Bairro Morro Preto, Muzambinho, MG 37890-000, Brasil.

4 Departamento de Patologia Animal, Universidade de Franca (Unifran), Rua Jorge Tibiriçá s/n, Franca, SP 14404-626, Brasil.
}

transição epitélio-mesênquima, caracterizado pela troca dos filamentos intermediários de citoqueratina por vimentina, além da perda da proteína de adesão entre células (E-caderina) está relacionado com a maior ocorrência de metástase. Diante disto, objetivou-se avaliar, por meio de imunomarcações, a expressão de vimentina, citoqueratina e E-caderina nos tumores mamários caninos e suas metástases em linfonodo, a fim de avaliar o comportamento celular frente a esta neoplasia. Foram analisados cinco casos de neoplasias mamárias primárias caninas e suas respectivas metástases em linfonodos. Foram comparadas as médias de imunomarcações do grupo de neoplasias primárias com as médias do grupo metástase. Não houve diferença esta- 
tística nas imunomarcações da citoqueratina $(p=0,1407)$ e E-caderina $(p=0,312)$ entre os grupos, apesar da média de expressão da E-caderina ter sido maior no grupo de metástases. A expressão da vimentina foi maior nos sítios das metástases ( $\mathrm{p}=0,0462)$. Conclui-se que a expressão de vimentina aumenta no foco da metástase em relação aos seus respectivos tumores primários mamários caninos, caracterizando alteração estrutural celular, conferindo um fenótipo transição epitélio-mesênquima. Além da E-caderina apresentar fortes indícios de aumento no foco da metástase caracterizando maior adesão.

TERMOS DE INDEXAÇÃO: Cães, invasão, oncologia, proteínas, tumores mamários, linfonodo.

\section{INTRODUÇÃO}

Invasão e metástase são atributos biológicos das células neoplásicas que influenciam diretamente o prognóstico. Devido a maior disponibilidade de anticorpos para imuno-histoquímica na espécie canina, várias pesquisas estão sendo realizadas para fornecer informações sobre as transformações celulares que acontecem durante a carcinogênese e o processo metastático (Khanna \& Hunter 2005, Hollier et al. 2009). No processo de invasão dos tecidos adjacentes pela neoplasia, há uma diminuição na adesão entre as células e estas adquirem mobilidade e atividades proteolíticas apresentando características mesenquimais semelhante ao processo que acontece na transição epitélio-mesênquima (epithelial-mesenchymal transition-EMT) da fase embrionária (Makdissi 2006).

Durante o processo de EMT, estruturas do citoesqueleto são reorganizados e a actina periférica é trocada por fibras de tensão, enquanto que filamentos intermediários de citoqueratina são trocados por vimentina. Tais mudanças concomitantes alteram as células de um formato cuboide para fusiforme e enfim, estas adquirem capacidade de invadir e se movimentar na matriz extracelular com ausência de ligação entre as células (Hay 1995, Hollier et al. 2009, Taylor et al. 2010).

A presença de E-caderina, associada à perda ou redução de vimentina é característica das células epiteliais, sendo que o contrário é observado nas células mesenquimais. Curiosamente, este padrão mesenquimal de expressão é observado em culturas de células epiteliais neoplásicas que apresentam um fenótipo agressivo e migratório. Deste modo, o aumento da expressão de vimentina associado a falta de expressão e/ou localização de E-caderina e catenina está relacionado com migração de células tumorais (Gilles et al. 2003, Kokkinos et al. 2007, Onder et al. 2008). A forte marcação de vimentina em células neoplásicas epiteliais está ligada com maior migração e invasão tumoral (Korsching et al. 2005).

Estudos evidenciaram que o local secundário/metastático pode induzir a reexpressão de E-caderina e consequente reversão da transição epitélio mesenquima (mesenchymal to epithelial reverting transition-MErT), o que confere alteração comportamental das células neoplásicas e por isso ser considerado um importante passo para a sobrevivência destas no sítio metastático (Chao et al. 2010).

A utilização de melhores marcadores de diagnóstico e prognóstico, proteínas ou genes, são importantes para determinar melhor os resultados clínicos, a fim do tratamento ser mais adequado, evitando subdoses ou sobredoses de quimioterápicos ou outros tratamentos (Knudsen \& Wheelock 2005).

Diante de poucos estudos na cadela sobre a EMT em neoplasias mamárias, e com intuito de avaliar o comportamento das células metastáticas, almeja-se nesse estudo verificar a imunomarcação de citoqueratina, vimentina e E-caderina nas células neoplásicas mamárias primárias e em suas respectivas metástases em linfonodo.

\section{MATERIAL E MÉTODOS}

O projeto foi aprovado pelo Comitê de Ética na Utilização de Animais (CEUA) da Universidade de Franca (Unifran/SP) e tem como protocolo de registro o número 018/13.

Os blocos de parafina utilizados foram provenientes do arquivo do Setor de Patologia Animal da UNIFRAN, totalizando cinco casos de cães com carcinomas simples (carcinoma mamário sólido grau II, carcinoma micropapilar, carcinoma mamário sólido grau II, carcinoma mamário papilar grau III, carcinoma mamário papilar grau II) com metástase em linfonodo. Os cortes foram separados em grupo 1 (tumores malignos primários) e grupo 2 (linfonodos) e as neoplasias classificadas de acordo com Cassali et al. (2011). No presente estudo selecionou-se casos de carcinoma simples, uma vez que em cadelas os carcinomas simples são mais agressivos (Misdorp 2002).

A técnica imuno-histoquímica empregada foi o sistema de detecção livre de biotina $\left(\right.$ REVEAL $\left.^{\circledR}\right)$. A recuperação antigênica foi realizada com EDTA pH 8,5 em panela de pressão elétrica (ELITE PLATIUM $^{\circledR}$ ). 0 bloqueio da peroxidase endógena foi realizado com a aplicação do Bloqueador de Peroxidase (reagente do kit Reveal Spring ${ }^{\circledR}$ ). A seguir, os sítios inespecíficos foram bloqueados com solução bloqueadora de reação inespecífica (Reagente do kit Reveal Spring ${ }^{\circledR}$, Cod SPD-125). Foram utilizados os anticorpos monoclonais, do fabricante Santa cruz, anti citoqueratina e anti vimentina, com diluições de 1:50, sendo os clones AE1/AE3 e V9, respectivamente. Além do policlonal anti E-caderina, clone IM0066, diluição de 1:50, do fabricante Immunity. Todos eles foram incubados a $4^{\circ} \mathrm{C}$ por 18 horas. Seguiu-se a incubação com o polímero ligado a peroxidase, (Polímero Reveal HRP, kit Spring- cod SPD-125), aplicação do DAB e contra corados com Hematoxilina de Harris, conforme orientação do fabricante.

Foram realizadas as contagens das células imunomarcadas em microscópio de luz binocular (Nikon E200) com equipamento para fotomicrografia digital. Antes da contagem, foram feitas observações quanto ao tipo de células marcadas e a distribuição da marcação. Para o anticorpo vimentina só foram contadas as células epiteliais que expressaram vimentina. Para quantificar as células imunomarcadas foram aleatoriamente selecionados quatro campos por corte e foi contado um total de 100 células entre as marcadas e as não marcadas, utilizando-se objetiva de 40x. Foi realizada uma média dos quatro campos observados, por lâmina, totalizando a porcentagem de células marcadas (Magalhães et al. 2012). Como controle positivo interno foi utilizado o epitélio cutâneo para a citoqueratina e E-caderina e fibroblastos para a vimentina. Como controle negativo aplicou-se apenas o diluente de anticorpo (BSA- bovine serum albumim 5\%). As análises estatísticas foram realizadas nas comparações das médias do grupo 1 e médias do grupo 2. 0 teste estatístico utilizado foi o teste paramétrico T de Student, comparando as imunomarcações entre os dois grupos para cada uma das proteínas estudadas. Adotou-se significância de 5\%. 


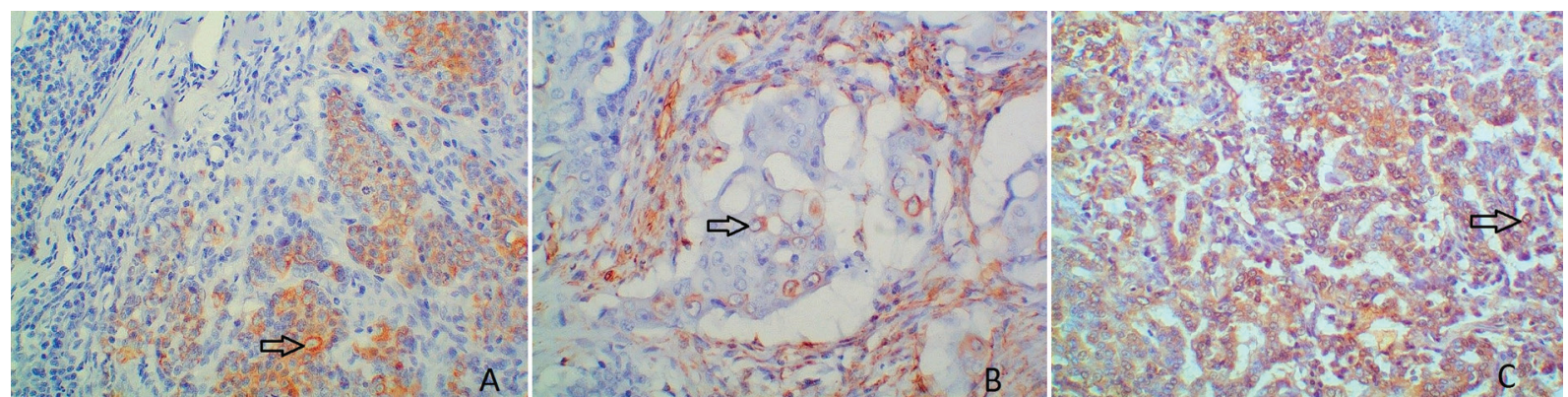

Fig.1. (A) Metástase de carcinoma mamário sólido grau II em linfonodo sentinela de cadela; presença de marcação citoplasmática nas células epiteliais mamárias neoplásicas (seta). Imuno-histoquímica, anticorpo primário citoqueratina (AE1/AE3). (B) Metástase de carcinoma mamário papilar grau II em linfonodo sentinela de cadela; presença de marcação citoplasmática nas células mamárias neoplásicas (seta preta). Imuno-histoquímica, anticorpo primário vimentina (V9). (C) Metástase de carcinoma mamário papilar grau II em linfonodo sentinela; presença de marcação em membrana plasmática e citoplasmática nas células mamárias neoplásicas (seta). Imuno-histoquímica, anticorpo primário E-caderina (IM-0066). Método Reveal, livre de biotina, cromógeno DAB, contra-coloração Hematoxilina, obj.40x.

\section{RESULTADOS}

As imunomarcações para citoqueratina foram citoplasmáticas com acentuada imunomarcação tanto nas células epiteliais do tumor primário, quanto nas células epiteliais metastáticas. Para este anticorpo, pode-se verificar que não houve diferença entre as médias de imunomarcação no tumor primário e metástase $(\mathrm{p}=0,1407)$, sendo a média de expressão nos tumores primários de $51,40 \pm 13$,89 e a média da imunomarcação nas metástases de 59,60ะ6,11.

Para o anticorpo vimentina as imunomarcações foram citoplasmáticas com maior média nas metástases do que nas neoplasias primárias. A diferença entre as imunomarcações foi significativa, obtendo maior marcação nos sítios metastáticos do que nos tumores primários $(\mathrm{p}=0,0462)$, sendo a média de imunomarcação nos tumores primários

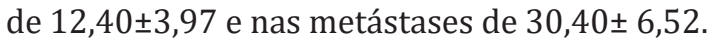

Os resultados das imunomarcações de E-caderina foram maiores no sítio da metástase, porém sem significado estatístico $(\mathrm{p}=0,312)$, com média de imunomarcação no tumor primário $23,20 \pm 10,92$ e na metástase 41,20 $\pm 12,65$. As imunomarcações para E-caderina ocorreram em membrana plasmática e citoplasma. As imunomarcações, para as três proteínas, nas metástases em linfonodo estão ilustradas na Figura 1.

\section{DISCUSSÃO}

Geralmente a expressão de vimentina em células epiteliais está relacionada com a ausência de E-caderina dentre outras moléculas de adesão e proteínas sinalizadoras. Por essa ausência de adesão, acredita-se que a maior expressão de vimentina esteja também ligada a uma maior invasão celular e ocorrência de metástase em linhagens de carcinoma de mama, bexiga, cólo de útero, cólon e outros. No carcinoma mamário, a presença de vimentina indica progressão da enfermidade com pior prognóstico (Islam et al. 2000). Nesse estudo foram observadas em média 12,4\% de células imunomarcadas para vimentina em neoplasias mamárias primárias, já caracterizando tendência à invasão tumoral. Acredita-se que o processo EMT e a migração coletiva estejam relacionados à disseminação metastática dos tumores mamários caninos e que a imunomarcação de vimentina possa ser um indício de mau prognóstico nos carcinomas mamários em cadelas (Terra 2010).

A ausência de expressão das E-caderinas parece ser um pré-requisito para promoção da disseminação das células neoplásicas e pode ocorrer por uma diminuição transitória na expressão da molécula durante o início do processo de desenvolvimento da mestástase ou pela emergência de clones celulares em neoplasias primárias com modificações genéticas causando uma diminuição na expressão dessa proteína (Van der Wurff et al. 1994, Kashiwagi et al. 2010). Este fato foi observado nesta pesquisa na qual a média de expressão de E-caderina foi menor no tumor primário comparado-se ao foco de metástase. Estudos relatam que há maior imunomarcação de E-caderina em vasos linfáticos e no sítio metastático podendo ser justificada pela fixação das células no ambiente novo, a fim de estabelecer uma nova arquitetura. Por isso, a reexpressão desta proteína de adesão por células tumorais depois da disseminação do local primário pode ser importante para que estas células fiquem aderidas em sítios distantes (Brunetti et al. 2003).

Resultados semelhantes foram observados por Chao et al. (2010) que verificaram um aumento da reexpressão de E-caderina no sítio metastático consistindo em uma reversão parcial da transição epitélio mesenquima (MErT) que permite uma segunda transição epitélio mesenquima no sítio metastático de tumores de mama e próstata de humanos. Essa mudança fenotípica reflete um comportamento celular alterado e que pode ser um passo importante de sobrevivência da célula neoplásica na metástase. Tais foram detectados neste trabalho, onde a imunomarcação da proteína E-caderina foi maior na metástase quando comparado ao sítio primário.

Sugere-se que a transição epitélio mesenquima ocorra seguida da reversão no sítio metastático para gerar metástases secundárias e que a persistência das características mesenquimais na MErT, apesar da reexpressão dos marcadores epiteliais e de moléculas de adesão, permita que as células neoplásicas metastáticas se adaptem ao ambiente novo (Chao et al. 2010). Assim como ocorre em nos carcinomas mamários em mulher, nesse estudo um carcinoma micropapilar apresentou metástases em linfonodo e pulmão, sugerindo que a reversão da MErT possa ocorrer em alguns tipos de carcinomas mamários na cadela. 
São escassos os estudos sobre o fenótipo transição epitélio-mesênquima nas neoplasias mamárias primárias, sobretudo comparando com sítio respectivo de metástases, fato inédito relatado neste estudo. Nesta pesquisa observou-se um aumento significativo da vimentina e uma tendência ao aumento da E-caderina no sítio da metástase, caracterizando uma maior adesão entre essas células e uma alteração estrutural respectivamente. Não só no câncer de mama como nos outros tipos de neoplasia, o fenômeno EMT dificilmente ocorre de forma homogênea em todo o tumor. Por meio da averiguação da expressão de marcadores específicos, especula-se que ele ocorra de forma mais focal na região invasiva da neoplasia e que neste caso as células são incitadas a realizar o fenômeno por alterações genéticas e epigenéticas (Hollier et al. 2009, Micalizzi et al. 2010).

Ainda é questionável se são as próprias células tronco da mama, suas progenitoras ou as células mais diferenciadas que adquirem propriedades de células tronco e representam as verdadeiras células precursoras da neoplasia. Compreender melhor a hierarquia celular da mama é fundamental, além de entender como a comunicação entre o epitélio e o estroma é conservada e, como isso interfere na progressão do tumor mamário. A plasticidade intrínseca do epitélio relacionada com sua capacidade de lidar com agentes externos e mudar o fenótipo para mesenquimal via EMT é importante, principalmente por ter indícios de relação do EMT na resistência aos medicamentos e na recidiva tumoral (Ingthorsson et al. 2016).

\section{CONCLUSÃO}

Conclui-se que as imunomarcações para vimentina está aumentada e com fortes indícios de aumento de E-caderina no foco da metástase em relação aos seus respectivos tumores primários mamários caninos caracterizando maior adesão e alteração estrutural celular, conferindo um fenótipo transição epitélio-mesênquima.

\section{REFERÊNCIAS}

Brunetti B., Sarli G., Preziosi R., Leprotti S. \& Benazzi C. 2003. E-cadherin expression in canine mammary carcinomas with regional lymph node metastases. J. Vet. Med. A 50:496-500.

Chao Y.L., Shepard C.R. \& Wells A. 2010. Breast carcinoma cells re-express E-cadherin during mesenchymal to epithelial reverting transition. Molecular Cancer 9:179.

Cassali G.D., Lavalle G.E., Ferreira E., Estrela-Lima A., De Nardi A.B., Ghever C., Sobral R.A., Amorim R.L., Oliveira L.O., Sueiro F.A.R., Beserra H.E.O., Bertagnolli A.C., Gamba C.O., Damasceno K.A., Campos C.B., Araujo M.R., Campos L.C., Monteiro L.N., Nunes F.C., Horta R.S., Reis D.C., Luvizotto M.C.R., Magalhães G.M., Raposo J.B., Ferreira A.M.R., Tanaka N.M., Grandi F., Ubukata R., Batschinski K., Terra E.M., Salvador R.C.L., Jark P.C., Delecrodi J.E.R., Nascimento N.A., Silva D.N., Silva L.P., Ferreira K.C.R.S., Frehse M.S., Di Santis G.W., Silva E.O., Guim T.N., Kerr B., Cintra P.P., Silva F.B.F., Leite J.S., Mello M.F.V., Ferreira M.L.G., Fukumasu H., Salgado B.S. \& Torres R. 2011. Consensus for the diagnosis, prognosis and treatment of canine mammary tumors. Braz. J. Vet. Pathol. 4:153-180.
Gilles C., Polette M., Metsdagt M., Nawrocki-Raby B., Ruggeri P., Birembaut P. \& Foidart J.M. 2003. Transactivation of Vimentin by $\beta$-catenin in human breast cancer cells. Cancer Res. 63:2658-2664.

Hay E.D. 1995. An overview of epithelio-mesenchymal transformation. Acta Anat. 154:8-20.

Hollier B.G., Evans K. \& Mani S.A. 2009. The epithelial-to-mesenchymal transition and cancer stem cells: a coalition against cancer therapies. J. Mammary Gland Bio. Neo. Archs 14:29-43.

Ingthorsson S., Briem E., Bergthorsson J.T. \& Gudjonsson T. 2016. Epithelial Plasticity During Human Breast Morphogenesis and Cancer Progression. J. Mammary Gland Bio. Neo. Archs 21:139-148.

Islam S., Kim J.B., Trendel J., Wheelock M.J. \& Johnson K.R. 2000. Vimentin expression in human squamous carcinoma cells: relationship with phenotypic changes and cadherin-based cell adhesion. J. Cell Biochem. 78:141-150.

Khanna C. \& Hunter K. 2005. Modelling metastasis in vivo. Carcinogenesis 26:513-523.

Kashiwagi S., Yashiro M., Takashima T., Nomura S., Noda S., Kawajiri H., Ishikawa T., Wakasa K. \& Hirakawa K. 2010. Significance of E-cadherin expression in triple-negative breast cancer. Brit. J. Cancer 103:249-255.

Knudsen K.A. \& Wheelock M.J. 2005. Cadherins and the mammary gland. J. Cell Biochem.95:488-496.

Kokkinos M.I., Wafai R., Wong M.K., Newgreen D.F., Thompson E.W. \& Waltham M. 2007. Vimentin and epithelial-mesenchymal transition in human breast cancer - observations in vitro and in vivo. Cells Tissues Organs 185:191-203.

Korsching E., Packeisen J., Liedtke C., Hungermann D., Wulfing P., Van Diest P.J. \& Buerger H. 2005. The origin of vimentin expression in invasive breast cancer: epithelial-mesenchymal transition, myoepithelial histogenesis or histogenesis from progenitor cells with bilinear differentiation potential? J. Pathol. 206:451-457.

Magalhães G.M., Silveira A.C.T., Munari D.P. \& Alessi A.C. 2012. Behavior of $\mathrm{CD} 44$ receptors in mammary tumors of dogs. Open J. Vet. Med. 2:4851.

Makdissi F.B.A. 2006. Análise da expressão de E-caderina, snail e hakai em células epiteliais de tumor e tecido peritumoral de mulheres com carcinoma ductal invasivo da mama: correlação com comprometimento linfonodal. Dissertação de Mestrado, Universidade de São Paulo, São Paulo. 83p.

Micalizzi D.S., Farabaugh S.M. \& Ford H.L. 2010. Epithelial-Mesenchymal transition in cancer: parallels between normal development and tumor progression. J. Mammary Gland Bio. Neo. Archs 15:117-134.

Misdorp W. 2002. Tumors of the mammary gland, p.575-606. In: Meuten D.J. (Ed.), Tumors in Domestic Animals. 4th ed. Iowa State Press, Ames.

Onder T.T., Gupta P.B., Mani S.A., Yang J., Lander E.S. \& Weinberg R.A. 2008. Loss of E-cadherin promotes metastasis via multiple downstream transcriptional pathways. Cancer Res. 68:3645-3654.

Taylor M.A., Parvani J.G. \& Schiemann W.P. 2010. The pathofisiology of epithelial-mesenchymal transition induced by Transforming Growth Factor- $\beta$ in normal and malignant mammary epithelial cells. J. Mammary Gland Bio. Neo. Archs 15:169-190.

Terra E.M. 2010. TGF $\beta$, pSmad2, p53, p63, E-caderina e Vimentina como marcadores prognósticos em tumores espontâneos de mama de cadelas. Dissertação de Mestrado, Faculdade de Medicina Veterinária e Zootecnia, Campus de Botucatu, Universidade Estadual Paulista "Júlio de Mesquita Filho", Botucatu, SP. 65p.

Van der Wurff A.A.M., Arends W., Van der Linden E.P.M., Kate J.T. \& Bosman F.T. 1994. L-CAM expression in lymph node and liver metastases of colorectal carcinomas. J. Pathol. 172:177-182. 